\title{
Serum placental growth factor and soluble fms-like tyrosine kinase-1 in preeclamptic women at their third trimester of pregnancy
}

\author{
Nesreen A. Nasser ${ }^{1}$, Rayah S. Baban ${ }^{1} \oplus$, May F. Al-Habib ${ }^{2}$ and Risala A. Jameel ${ }^{3}$ \\ ${ }^{\mathrm{l}}$ Department of Chemistry and Biochemistry, College of Medicine, Al-Nahrain University, Baghdad, Iraq \\ ${ }^{2}$ Department of Anatomy, Histology and Embryology, College of Medicine, Al-Nahrain University, Baghdad, Iraq \\ ${ }^{3}$ Al-Immamain Al-Kadhimain Medical City, Iraqi Ministry of Health, Baghdad, Iraq
}

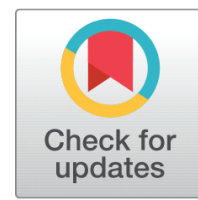

Received 02-10-2020

Revised 18-10-2020

Accepted 26-12-2020

Published 31-12-2020

\section{Corresponding Author}

Nesreen A. Nasser nena-

nena1987ahmednena@yahoo.com

College of Medicine, Al-Nahrain University, Baghdad, Iraq

DOI https://doi.org/10.47419/ bjbabs.v1i01.30

\section{Pages: 41-48}

Distributed under the terms of the Creative Commons Attribution-NonCommercial 4.0 International (CC-BY-NC 4.0), which permits use for any non-commercial purpose, distribution, and reproduction in any medium, provided that the original work is properly cited.

Copyright: (C) 2020 Nesreen A. Nasser, Rayah S. Baban, May F. Al- Habib, Risala A. Jameel

\section{ABSTRACT}

Background: Preeclampsia (PE) affects approximately 3\% of all pregnancies, and it is still a major cause of the adverse perinatal outcome. PE is a multisystem disease characterized by the development of hypertension and proteinuria. Although PE etiology is not fully known, the placenta seems to play a central role in the development of the disease. The inadequate placentation process results in a change in angiogenic factors levels, such as the soluble form of vascular endothelial growth factor receptor type 1 (sFlt-1) and placental growth factor (PLGF).

Objectives: To investigate the correlation between serum PLGF with soluble sFLT-1 in preeclamptic women at their third trimester.

Methods: A case-control study was carried out from August 2018 till January 2019. In this study, pregnant women were collected from the Al-Elweyia, Al-Hakeem, and Al-Imamain Alkadhimain medical city. The practical part was conducted at the College of Medicine, Al-Nahrain University. The patient group includes 50 preeclamptic women in the third trimester ( 25 mild and 25 severe). Fifty healthy pregnant women (at their third trimester of gestation) were selected as control. Patients and control were compared for age, serum PLGF, and Sflt-1.

Results: Serum PLGF levels were decreased significantly among women who developed PE $(2.14 \pm 0.029 \mathrm{pg} / \mathrm{ml}, 2.44 \pm 0.038 \mathrm{pg} / \mathrm{ml}$ vs. $2.68 \pm 0.017 \mathrm{pg} / \mathrm{ml} ; p<0.05)$ severe $\mathrm{PE}$, Mild PE, and the control group respectively, while, serum sFlt1 levels were increased significantly $(p<0.05)$ between the groups of $\mathrm{PE},(5.81 \pm 0.025$, $5.51 \pm 0.024,5.19 \pm 0.017 \mathrm{pg} / \mathrm{ml}$ ) severe, mild and control, respectively.

Conclusions: Serum sFlt- 1 and PLGF can be considered promising biomarkers for the preeclampsia. sFlt-1 and PLGF the ROC cut-offs $(5.67 \mathrm{ng} / \mathrm{ml}, 2.09 \mathrm{ng} / \mathrm{ml}$, respectively), the specificity and sensitivity of serum PLGF is more than that of serum sFlt-1, for the diagnosis of preeclampsia during the third trimester of pregnancy.

Keywords third trimester of pregnancy, preeclampsia, placental protein 13, sFLT-1, soluble fms-like tyrosine kinase 1, PLGF, placental growth factor

\section{OPEN ACCESS}




\section{INTRODUCTION}

Preeclampsia (PE), which affects $2-3 \%$ of pregnancies and is a major cause of maternal and perinatal morbidity and mortality, is thought to be the consequence of an imbalance in angiogenic and anti-angiogenic proteins. Several studies have reported that maternal serum levels of placental growth factor (PLGF) are reduced and those of soluble fms-like tyrosine kinase-1 (sFlt-1) are increased in women with PE. There is also evidence that the level of these proteins is altered before the onset of the clinical signs of the disease. However, a meta-analysis of such studies concluded that the test accuracies of serum PLGF and sFlt-1 before 30 weeks' gestation are too poor for accurate prediction of PE in clinical practice. ${ }^{1}$

Preeclampsia is associated with an altered maternal pattern of circulating placentally derived proteins regulating angiogenesis such as sFlt-1 (soluble fms-like tyrosine kinase 1) and PLGF (placental growth factor). ${ }^{2}$

Placental Growth Factor (PLGF) is a member of the vascular endothelial growth factor (VEGF) family and is predominantly expressed in the placenta, although it is also expressed at low levels in many other tissues, including the heart, lung, thyroid, liver, skeletal muscle and bone. The human PLGF gene is located on chromosome 14q14 and encodes four isoforms of PLGF. ${ }^{3}$

Soluble fms-like tyrosine kinase-1 (sFlt-1) is a tyrosine kinase protein with antiangiogenic properties. A non-membrane associated splice variant of VEGF receptor 1 (Flt-1), sFlt-1 binds the angiogenic factors VEGF (vascular endothelial growth factor) and PLGF (placental growth factor), reducing blood vessel growth through reduction of free VEGF and PLGF concentrations. In humans, sFlt-1 is important in the regulation of blood vessel formation in diverse tissues, including the kidneys, cornea, and uterus. Abnormally high levels of sFlt-1 have been implicated in the pathogenesis of preeclampsia. ${ }^{4}$

Serum PLGF is found to be decreased in women both at the time of diagnosis with preeclampsia and well in advance of syndrome onset. The deficiency in PLGF is likely due to a combination of decreased expression of PLGF and reduced free PLGF due to binding with sFLT-1, which is elevated in affected women. In early pregnancy, PLGF concentrations are lower in women who subsequently develop preeclampsia than in normal pregnant women, but sFLT-1 levels are no different, suggesting that PLGF expression in the placenta is decreased. However, towards completion of pregnancy, there is a reciprocal relationship between sFLT-1 and PLGF with rising levels of total (free and bound to VEGF or PLGF) sFLT-1 and lower free PLGF levels. This suggests that in the latter half of pregnancy, low PLGF concentrations occur predominantly due to the sequestering of PLGF by sFLT-1. ${ }^{5}$

\section{MATERIALS AND METHODS Study design and participants}

A case-control study was conducted. The patient groups include 50 preeclampsia women in the third trimester ( 25 mild, 25 severe). Fifty healthy pregnant women (at their third 
trimester of gestational) of six months from August 2018 till January 2019. Pregnant women included in this study were collected from the Al-Elweyia, Al-Hakeem, and Al- Imamain Alkadhimain Medical City. The practical work was conducted at the Department of Chemistry and Biochemistry, College of Medicine, Al-Nahrain University, and at the Department of Anatomy/ Histology and Embryology. This research was approved by the Institutional Review Board (IRB) of College of Medicine, Al-Nahrain University; before participation, all women were given an idea about the study, and their written informed consent was taken. All pregnant women included in this study were in the third trimester. Chronic hypertension, gestational hypertension, renal and liver diseases, diabetes mellitus, smokers, fetal structural anomalies, multiple pregnancies, intrauterine fetal growth restriction from other causes, heart failure, inflammatory disorders, elderly pregnant, infectious disease, endocrine disease, HELLP syndrome, and collagen vascular disease were excluded from this study.

\section{Blood sampling and biochemical analyses}

Samples collection blood samples were obtained from pregnant women in thirdtrimester pregnancy drawn. Five milliliters $(\mathrm{ml})$ of venous blood were withdrawn from all pregnant women using disposable syringes in the sitting position. The blood is discharged slowly into plain disposable test tubes without anticoagulant. The blood was allowed to clot at $37^{\circ} \mathrm{C}$ for $10-15$ minutes and then centrifuged at $1000_{x} \mathrm{~g}$ for 15 minutes. The serum stored in Eppendorf tubes at $-80^{\circ} \mathrm{C}$ until analysis of sFlt-1, and PLGF concentrations.

\section{Statistical analysis}

Data were analyzed by statistical packages of SPSS 18.5 (statistical packages for social sciences-version 18.5). All data were presented as a mean \pm SE. Statistical differences between the data of patients and control groups were determined according to the student t-test. $\mathrm{P}$ values of less than 0.05 were statistically significant.

\section{RESULTS}

Table 1 illustrates the age of preeclampsia patients and control groups analyzed by using one way ANOVA test. The mean \pm SE of maternal age for the pregnant control group and patients groups (mild and severe preeclampsia) were $29.28 \pm 1.08$ years, $29.84 \pm 1.70$ years, and $29.85 \pm 1.27$, respectively. No significant difference $(P<0.05)$ was found among all study groups. 
Table 1 The comparison of age between the control pregnant group and patients (mild and severe preeclampsia) groups at third trimester.

\begin{tabular}{|lllll} 
Type & Control & Mild PE & Severe PE & $\boldsymbol{P}$-value \\
Age (year) & $29.28 \pm 1.08$ & $29.84 \pm 1.70$ & $29.85 \pm 1.27$ & 0.931 \\
\hline
\end{tabular}

The mean \pm standard error of the mean of serum PLGF for control pregnant group and patients groups (mild and severe preeclampsia) at third trimester were $2.68 \pm 0.017 \mathrm{pg} / \mathrm{ml}$, $2.44 \pm 0.038 \mathrm{pg} / \mathrm{ml}$, and $2.14 \pm 0.029 \mathrm{pg} / \mathrm{ml}$, respectively.

Regarding serum PLGF, there was a significant difference $(p=0.047)$ between patients group (mild and severe) versus control group, $(p=0.048)$ mild preeclamptic group versus control pregnant group, $(p=0.006)$ severe preeclamptic group versus control pregnant group and ( $p=0.047$ ) mild preeclamptic group versus severe preeclamptic group in the third trimester at delivery respectively (Table2)

The mean \pm standard error of the mean of serum SFLT- 1 for control pregnant group and patients groups (mild and severe preeclampsia) at third trimester following delivery were $5.19 \pm 0.017 \mathrm{pg} / \mathrm{ml}, 5.51 \pm 0.024 \mathrm{pg} / \mathrm{ml}, 5.81 \pm 0.025 \mathrm{pg} / \mathrm{ml}$, respectively.

There were significant differences in the mean of SFLT-1 between patients groups (mild and severe preeclampsia) against the control group, mild preeclamptic group against control pregnant group, severe preeclamptic group against control group, severe preeclamptic group against the mild group in the third trimester of pregnancy $(p=0.042,0.032,0.027,0.043)$ respectively (Table 2).

\begin{tabular}{|c|c|c|c|c|c|c|}
\hline & & Mean \pm SEM & $\begin{array}{l}P \text { value } \\
\text { (between } \\
\text { all groups) }\end{array}$ & $\begin{array}{l}\text { Control } \\
\text { vs. } \\
\text { Mild }\end{array}$ & $\begin{array}{l}\text { Control } \\
\text { vs. } \\
\text { Severe }\end{array}$ & $\begin{array}{l}\text { Mild } \\
\text { vs. } \\
\text { Severe }\end{array}$ \\
\hline \multirow{3}{*}{$\begin{array}{l}\text { Serum PLGF } \\
\quad(\mathrm{pg} / \mathrm{ml})\end{array}$} & Control & $2.68 \pm 0.017$ & & & & \\
\hline & Mild & $2.44 \pm 0.038$ & 0.047 & 0.048 & 0.006 & 0.047 \\
\hline & Severe & $2.14 \pm 0.029$ & & & & \\
\hline \multirow{3}{*}{$\begin{array}{l}\text { Serum sFlt-1 } \\
\qquad(\mathrm{pg} / \mathrm{ml})\end{array}$} & Control & $5.19 \pm 0.017$ & & & & \\
\hline & Mild & $5.51 \pm 0.024$ & 0.042 & 0.032 & 0.027 & 0.043 \\
\hline & Severe & $5.81 \pm 0.025$ & & & & \\
\hline
\end{tabular}

Receiver operating characteristic curve (ROC) analyses of serum placental growth factor PLGF demonstrated the ability of this marker to differentiate preeclamptic from normal pregnancies (Figure 1). In this figure, the cut-off value $=2 \mathrm{pg} / \mathrm{ml}$ optimally identified the patients with preeclampsia; at this cut-off value, the sensitivity was $57 \%$, and specificity was $65 \%$, and the area under the curve (AUC) was 0.608 . The ROC analyses of serum soluble fms-like tyrosine kinase (SFLT-1) (Figure 2) demonstrated the ability of this marker to differentiate preeclamptic from normal pregnancies (Figure 2). In this figure, the cut-off value 
$=5.58 \mathrm{pg} / \mathrm{ml}$ optimally identified the patients with preeclampsia; at this cut-off value, the sensitivity was $53 \%$, and specificity was $57.5 \%$, and the area under the curve (AUC) was 0.544 .

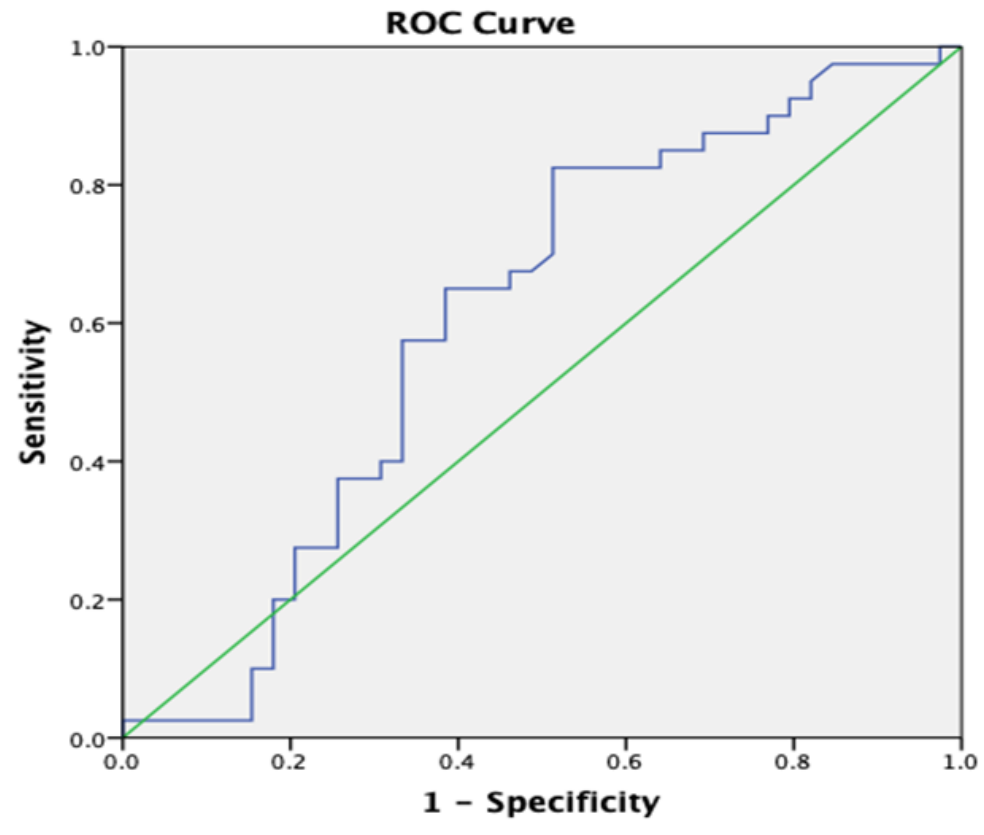

Diagonal segments are produced by ties.

Figure 1 Receiver operating characteristic curve (ROC) analysis of PLGF

\section{DISCUSSION}

The present study showed increases in the levels of serum soluble fms-like tyrosine kinase-1 in preeclampsia (mild and severe) compared with the pregnant control group in the third trimester. The sflt- 1 concentration is higher in the severe preeclamptic group in comparison with the mild preeclamptic group in the third trimester. Similar results were reported by many studies like Tsiakkas et. al., study. ${ }^{6}$

As the elevated serum levels of sFlt-1 modify the endothelial integrity of blood vessels, hence causing hepatic edema as well as hypertension and proteinuria encountered in preeclamptic patients. Also, blood-brain-barrier damage may occur, leading to brain edema. This aberrant angiogenesis and hypertension are the hallmarks of preeclampsia. ${ }^{7}$

Rizos et. al., confirmed that increased serum sFlt-1 levels early in pregnancy are associated with a higher risk of preeclampsia. ${ }^{8}$

The present study showed a decrease in the mean serum levels of PLGF in preeclamptic women in the third trimester as compared to the control pregnant women group; many studies like (Radulescu et al., 2016) reported similar results. ${ }^{9}$ 


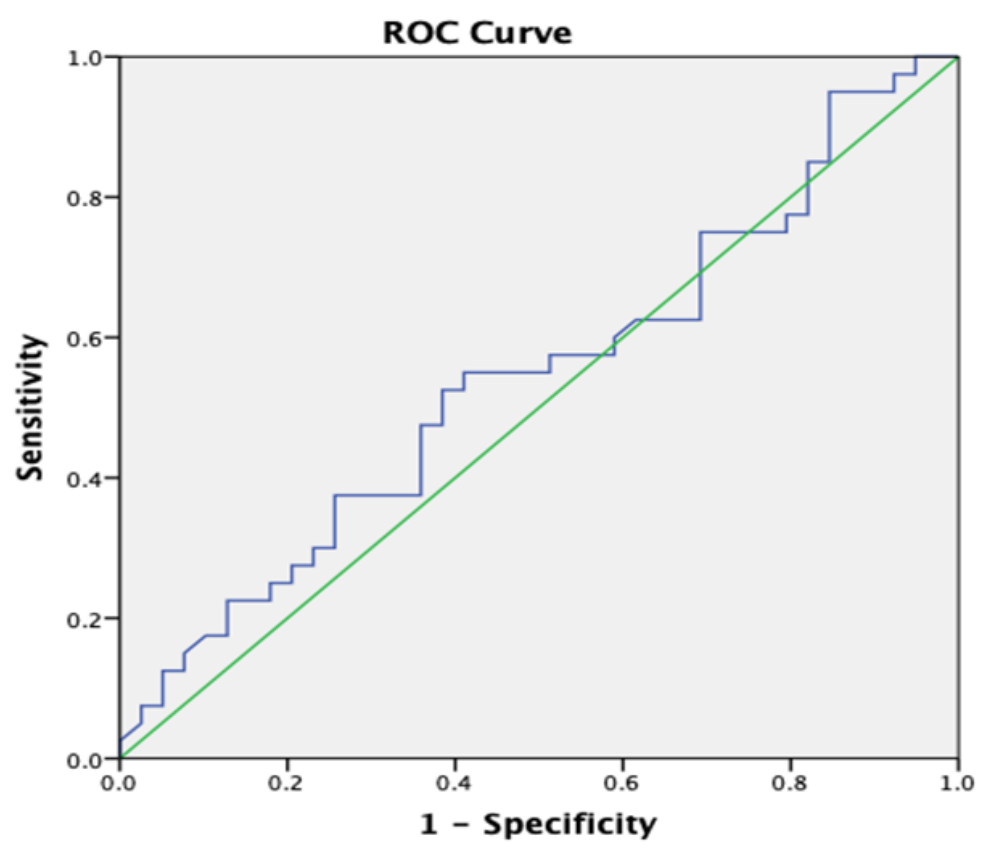

Diagonal segments are produced by ties.

Figure 2 Receiver operating characteristic curve (ROC) analysis of Sflt-1.

Rizos et. al., confirmed decreased serum PLGF levels early in pregnancy are associated with a higher risk of preeclampsia. ${ }^{8}$

The connection between circulating sFlt-1 and PLGF in preeclampsia was explored by previous studies suggesting that up-regulation of the anti-angiogenic sFlt-1 in preeclampsia leads to binding of the angiogenic factor PLGF, with a consequent decrease in circulating free PLGF levels. ${ }^{10}$ In this respect, sFlt- 1 and PLGF seem to be important etiological factors in preeclampsia's pathogenesis. ${ }^{7}$

\section{CONCLUSION}

Soluble fms-like tyrosine- 1 and PLGF levels changes in the third trimester during pregnancy; stress period, which reflect an association with its role in the pathogenesis of PE. So, the anti-angiogenic factors mentioned above could be used as biomarkers for disease progression \& impact on the outcome of pregnancy. Serum sFLT-1 levels of these markers in the third trimester were significantly correlated with the severity of preeclampsia in which they increased in the severe preeclampsia group compared to the serum concentration of both mild preeclampsia group and normal pregnant women group. 


\section{ACKNOWLEDGMENTS}

None.

\section{DECLARATIONS}

\section{Authors' contributions}

All authors have equally contributed to this research. They reviewed and approved the final version of this article before publication.

\section{Conflict of interest}

There are no conflicts of interest to declare.

\section{Ethical approvals}

This research was approved by the Institutional Review Board (IRB) of the College of Medicine, Al-Nahrain University. Before participation, all participants were given an idea about the study, and their written informed consent was taken.

\section{Data availability}

The data that support the findings of this study are available from the corresponding author, upon reasonable request.

\section{Funding resources}

This work didn't receive any fund.

\section{REFERENCES}

1. Powe CE, Levine RJ, Karumanchi SA. Preeclampsia, a disease of the maternal endothelium: The role of antiangiogenic factors and implications for later cardiovascular disease. Circulation. 2011;123(24):2856-2869.

2. Jena MK, Sharma NR, Petitt M, Maulik D, Nayak NR. Pathogenesis of Preeclampsia and Therapeutic Approaches Targeting the Placenta. Biomolecules. 2020;10(6):953-953. Available from: 10.3390/biom10060953;https://dx.doi.org/10. 3390/biom10060953.

3. Chau K, Hennessy A, Makris A. Placental growth factor and pre-eclampsia. Journal of Human Hypertension. 2017;31(12):782-786. Available from: 10.1038/jhh.2017. 61; https://dx.doi.org/10.1038/jhh.2017.61.

4. Luft FC. Soluble fms-like tyrosine kinase-1 and atherosclerosis in chronic kidney disease. In Kidney International. 2014;85(2):238-240.

5. Hoeller A, Ehrlich L, Golic M, Herse F, Perschel FH, Siwetz M, et al. Placental expression of sFlt-1 and PlGF in early preeclampsia vs. early IUGR vs. age-matched healthy pregnancies. Hypertension in Pregnancy. 2017;36(2):151-160. Available from: 10. 
1080/10641955.2016.1273363;https://dx.doi.org/10.1080/10641955.2016.1273363.

6. Tsiakkas A, Duvdevani N, Wright A, Wright D, Nicolaides KH. Serum soluble fms-like tyrosine kinase- 1 in the three trimesters of pregnancy: effects of maternal characteristics and medical history. Ultrasound in Obstetrics \& Gynecology. 2015;45(5):584-590. Available from: 10.1002/uog.14817;https://dx.doi.org/10.1002/ uog. 14817.

7. Gurnadi JI, Mose J, Handono B, Satari MH, Anwar AD, Fauziah PN, et al. Difference of concentration of placental soluble fms-like tyrosine kinase-1(sFlt-1), placental growth factor (PlGF), and sFlt-1/PlGF ratio in severe preeclampsia and normal pregnancy. BMC Research Notes. 2015;8(1). Available from: 10.1186/s13104-0151506-0;https://dx.doi.org/10.1186/s13104-015-1506-0.

8. Rizos D, Eleftheriades M, Karampas G, Rizou M, Haliassos A, Hassiakos D, et al. Placental growth factor and soluble fms-like tyrosine kinase-1 are useful markers for the prediction of preeclampsia but not for small for gestational age neonates: a longitudinal study. European Journal of Obstetrics \& Gynecology and Reproductive Biology. 2013;171(2):225-230. Available from: 10.1016/j.ejogrb.2013.08.040; https: //dx.doi.org/10.1016/j.ejogrb.2013.08.040.

9. Rădulescu C, Bacârea A, Huțanu A, Gabor R, Dobreanu M. Placental Growth Factor, Soluble fms-Like Tyrosine Kinase 1, Soluble Endoglin, IL-6, and IL-16 as Biomarkers in Preeclampsia. Mediators of Inflammation. 2016;2016:1-8. Available from: 10. 1155/2016/3027363;https://dx.doi.org/10.1155/2016/3027363.

10. Lapaire O, Shennan A, Stepan H. The preeclampsia biomarkers soluble fms-like tyrosine kinase-1 and placental growth factor: current knowledge, clinical implications and future application. European Journal of Obstetrics \& Gynecology and Reproductive Biology. 2010;151(2):122-129. Available from: 10.1016/j.ejogrb.2010. 04.009; https://dx.doi.org/10.1016/j.ejogrb.2010.04.009. 